\title{
EL PAISAJE COMO INTERFAZ (EXPERIENCIA ESTÉTICA Y METAFÍSICA)
}

\author{
Raúl Cadús \\ Universidad Nacional del Comahue \\ raulcadus@gmail.com
}

\section{RESUMEN}

El presente artículo trata acerca del paisaje como nexo entre la experiencia estética y la cuestión del ser, con el fin de destacar el potencial epistemológico de aquél en relación con el pensamiento y la experiencia del principal asunto de la metafísica. A partir de un análisis del paisaje en perspectiva ontológica, éste se revela especialmente apto para el desarrollo de una metafísica-estética como camino de indagación y de experiencia, haciendo posible un replanteo de la metafísica como actividad entre la teoría y la práctica. En primer lugar ofrecemos una introducción a la experiencia estética-metafísica en perspectiva histórica, para exponer a continuación dos perspectivas ontológicas sobre el paisaje: a) como parte de una serie ontológica mayor y como coproducción subjetiva-objetiva; b) como protoarte de la naturaleza, obra de arte y arte de los pueblos.

PAlabras Clave: paisaje, interfaz, saber, experiencia estética, metafísica.

THE LANDSCAPE AS AN INTERFACE

(AESTHETIC AND METAPHYSICAL EXPERIENCE)

\section{Abstract}

This article deals with landscape as a nexus between the aesthetic experience and the metaphysical issue of Being, in order to highlight its epistemological power linked with thinking and experiencing the Being. On the basis of a landscape analysis made from an ontological perspective, it reveals itself as a specially qualified phenomenon for the development of a Metaphysics-esthetics as an inquiring and experiencing way, enabling a reconsideration of Metaphysics as theory and practice. Firstly I present an introduction to the metaphysics-esthetics experience from a historical perspective, to expose next two ontological perspectives on landscape: a) as a part of a larger ontological chain and a subjective-objective co-production; b) as a proto-art of Nature, artwork and art of peoples.

KEYwORDs: landscape, interface, learning, aesthetic experience, metaphysics. 


\section{INTRODUCCIÓN}

Son muchas las aproximaciones teóricas a la cuestión del paisaje que han tenido lugar en los últimos 40 años, promoviendo un sinfín de estudios inter- y transdisciplinares que actualmente abonan el campo de los estudios culturales, la geografía humana y las artes, así como el campo de los estudios relacionados con la problemática ambiental y el urbanismo. Desde la filosofía también se ha incrementado el interés por el tema, sobre todo desde la estética, en relación con el paisajismo y el arte milenario de la jardinería, pero también en función del propio desarrollo de la cuestión del arte y su corrimiento hacia expresiones que contemplan el arte ambiental y el arte ecológico, revitalizando la problemática de la modernidad tardía en relación con la cuestión de la experiencia estética de la naturaleza, en el contexto de un mundo marcado por el desastre ecológico y las migraciones forzadas. Esto es, a partir de unas experiencias que en un contexto epistémico ubicarían a la cuestión del paisaje en el marco de las geofilosofías contemporáneas, a la sazón interesadas por las relaciones entre el ser humano y el territorio. En la vereda de enfrente de esta perspectiva teórica se encontrarían los desarrollos de un modelo formalista, para el que los valores estéticos sólo pueden concebirse a partir de las relaciones entre los elementos internos de la obra (considerado el paisaje como tal), que igualmente ha surgido en estos últimos 40 años, y que, junto con el «modelo atmosférico» y el «ecológico» ${ }^{1}$, representan una actualización de las disputas de fines del siglo XVIII en torno a la pureza y/o la mixtura de la experiencia estética con otros tipos de experiencia. Independientemente de los resultados, ambas perspectivas implican por igual un abordaje exclusivamente teórico del asunto, que en todo caso se dirime entre unas aproximaciones más o menos analíticas, fenomenológicas o hermenéuticas, que apuntan a dar cuenta de las problemáticas en cuestión. Por nuestra parte, en cambio, si bien nos hacemos cargo de las principales discusiones que van teniendo lugar de manera creciente en contextos académicos, así como de la problemática ontológica de carácter teórico en torno al fenómeno del paisaje, reivindicamos una perspectiva práctica desde la que se revalida la idea de un saber experiencial para la metafísica, respecto del cual el paisaje cumpliría un rol fundamental. Para el desarrollo de nuestro planteo nos remitimos de manera implícita a esa instancia inaugural en la filosofía del paisaje que representa el ensayo de George Simmel Filosofía del paisaje (de 1913), en el que por primera vez se perfila el tema en clave ontológica, como una cuestión contigua pero aparte de la filosofía de la naturaleza precedente, al tiempo que nos remontamos a los orígenes mismos de la filosofía siguiendo el hilo de la experiencia estética en relación con la experiencia metafísica.

${ }^{1}$ Cf. P. D’Angelo, Filosofia del paesaggio, Quodlibet, Macerata, 2014, cap. IV. 


\section{EL SABER ESTÉTICO-METAFÍSICO}

Las relaciones entre la experiencia estética y la metafísica se remontan muy atrás en el tiempo y se podría decir que hasta los orígenes mismos de la humanidad, ya que más allá de las instituciones del arte y del conocimiento se trata de una relación entre esferas de la experiencia inherentes al ser humano en cuanto tal, como son las implicadas en la percepción de la belleza y el misterio ${ }^{2}$. Así lo atestiguan filosofías muy diversas, al igual que la experiencia, pudiendo dar, cualquiera de nosotros, con el factum de la belleza que siempre trae consigo un goce sensible. Todos hemos experimentado la belleza y sabemos qué es bello, aunque sólo algunos se dediquen a conceptualizarlo. Mientras que la experiencia metafísica -entendida como la experiencia vinculada con cuestiones que trascienden la materialidad física ordinaria- también es una experiencia que podríamos considerar «común», presente, por ejemplo, en el amor por el que uno puede llegar a sentir y hasta ser por otro, en la experiencia religiosa -que generalmente también se manifiesta como una experiencia amorosa- e incluso en la experiencia de nuestra propia existencia que nos pone ante la finitud y la muerte. Sin duda que se trata de dos tipos de experiencias bien distintas, que sin embargo se hallan estrechamente vinculadas entre sí y que la filosofía ha relacionado desde hace tiempo. Podríamos decir que desde Platón, justamente en relación con el problema del ser concebido como el problema del ente supremo, dificultosamente accesible a la razón (y en eso consiste la ardua tarea de elaborar su ciencia) pero igualmente asequible al alma por intermediación de la belleza ${ }^{3}$. Motivo que tendrá algún eco en el Medioevo cristiano, dentro de la tradición platónica y con el límite insuperable de una absoluta trascendencia del ser supremo respecto de la sensibilidad, pero que igualmente tendrá cabida en la experiencia de la biblia pauperum que apela al poder de las imágenes para la enseñanza moral-teológica, lo mismo que en el arte desde el Renacimiento, no ya como un camino de ascenso, como en el platonismo, aunque sí con vistas a la suscitación

${ }^{2}$ Hacemos referencia a la experiencia de la belleza como caso testigo de la experiencia estética pero sin reducir ésta a aquélla. En líneas generales entendemos por experiencia estética todo tipo de interacción mediada esencialmente por la sensibilidad, en la que se lleva a cabo una modulación de la atención y de la afectividad (emociones) caracterizada, entre otras cosas, por la aprehensión (percepción o apercepción) de una cosa o acontecimiento como algo acabado en sí mismo, aun cuando no sepamos de qué se trata y aun cuando se encuentre en proceso, al tiempo que se alcanza un estado de ser más o menos momentáneo o permanente, caracterizado por el goce y por la generación de cierto saber. En líneas generales nos reconocemos afines a un horizonte pragmatista, de acuerdo al cual la experiencia estética es distinguible pero inseparable de otras esferas de la experiencia, reconociendo los rasgos kantianos, por así decir, del carácter impráctico de la experiencia estética (en cuanto tal) y el juicio de gusto como expresión de la misma. Cabe seńalar que esta estipulación, como la mayoría, destaca el aspecto de la recepción, debiendo ampliarse al considerar la experiencia estética desde el punto de vista de la producción.

3 Cf. Platón, Banquete, Orbis, Buenos Aires, 1983; xxix, 210-212. 
de un sentimiento metafísico ${ }^{4}$. Teorizadas por la filosofía, es posible ver en el giro estético que se produce en Europa con el Romanticismo, hacia fines del siglo XviII, un intento de desplegar la apertura de una metafísica-estética que se vincula con la experiencia de lo sublime en la naturaleza, que a la vez que es explorada por el arte (sobre todo por la pintura) desde la filosofía se la asimila a una experiencia del noumeno como aquella realidad profunda que se oculta tras los fenómenos. Incluso se abre la posibilidad de una metafísica-estética con eje en el concepto de belleza, tal como podemos observar en un fragmento del Proyecto: Programa de sistema más antiguo del idealismo alemán, donde se establece:

... Por último, la idea que todo lo unifica, la idea de la belleza, entendida la palabra en su más elevado sentido platónico. Estoy convencido de que el acto más elevado de la razón, aquél en que ella abraza todas las ideas, es un acto estético, y verdad y bondad sólo están hermanadas en la belleza. El filósofo debe poseer tanta fuerza estética como el poeta. Los hombres sin sentido estético son nuestros filósofos de letra imprenta. La filosofía del espíritu es una filosofía estética 5 .

Es conocida la aprensión del racionalismo ilustrado para con estas expresiones desde Kant, quien advierte acerca de los riesgos de las «filosofías del sentimiento» que ponen a la filosofía en el mismo plano que la literatura. Pero lo cierto es que se trata de una apertura virtual de la metafísica perfilada por él mismo en su Crítica del Juicio (al abordar el tema de lo sublime) tras la clausura que les propinara en su Crítica de la razón pura a las formas medievales y modernas de la metafísica especulativa ${ }^{6}$. De hecho, durante el siglo XIX predominó la importancia del problema moral ligado a la metafísica de una historia universal, igualmente trazada en sus lineamientos generales por Immanuel Kant, mientras que la apertura en clave de una metafísica-estética se resguardaría en la filosofía de Schelling como en la de Schopenhauer, pasando con éste a Nietzsche?

${ }^{4}$ Nos referimos, por ejemplo, al uso de paisajes montańosos de fondo, como el que pinta Da Vinci detrás de la famosa Gioconda, cuyo misterio entra en resonancia con el de aquél.

5 F. Hölderlin, G.W.F. Hegel y F.W.J. Schelling, «Proyecto (El Programa de sistema más antiguo del idealismo alemán, hacia 1795)», en J. Arnaldo (comp. y trad.), Fragmentos para una teoría romántica del arte, Tecnos, Madrid, 1987, p. 230. Cursivas en el original.

${ }^{6}$ En Critica de la Razón Pura Kant demuestra la inviabilidad de las Metafísicas especiales como ciencias (Psicología Racional, Cosmología y Teología) de acuerdo al nuevo concepto de conocimiento como síntesis entre las estructuras formales del sujeto y los datos sensibles del objeto, ya que estos últimos faltan en relación con Dios, el alma y el origen o fin del universo. A su vez hace de Dios, alma y mundo, ideas que no obstante testimonian nuestra naturaleza metafísica y la de dichos "objetos», mientras que en Crítica del Juicio, al tratar el tema de lo bello y lo sublime, da cuenta del carácter metafísico y experiencial de este último en una zona liminar con lo irrepresentable (inefable) del noumeno.

7 Como contraparte de la clausura kantiana de las Metaphysica specialis se sigue una doble apertura del horizonte de lo metafísico: la del ser como devenir, bajo la forma teorética de las filosofías de la Historia universal, y la de la experiencia (estética) de lo sublime. Encontrándose en esta última línea los desarrollos del perfil esteticista de la metafísica con posterioridad a Kant, sin deses- 
En la actualidad, el giro estético producido hacia fines del siglo XVIII en torno a las ideas del Romanticismo podría verse, pues -al menos desde la tesis que sostenemos- como un emergente epistémico que resurge en el marco de una generalizada estetización de la existencia en el siglo XXI, en un contexto completamente distinto para las metafísicas. Un contexto en el que los estudios parten de una radical deconstrucción de la sistematización racionalista con pensadores como Nietzsche y Heidegger, quienes de alguna manera habilitaron ya el pensamiento de lo metafísico bajo un paradigma esteticista, pero que sobre todo dieron lugar a la reivindicación de un saber experiencial para lo metafísico. Nietzsche a través de su «metafísica del artista», bajo la comprensión del arte como auténtica «actividad metafísica de la vida ${ }^{8}$, y Heidegger a través de su idea de un "hacer experiencia» mediante el habla (el pensar) como modo de acceder al pensamiento del ser ${ }^{9}$. En ambos casos dando lugar a la idea de una experiencia y un saber radicalmente diferentes de la conceptualización teórica, desde los que recuperamos la posibilidad de un saber experiencial de lo metafísico que pivota sobre la experiencia y la teoría del paisaje con relación al principal asunto de la metafísica: el ser mismo, la totalidad de lo existente y su misterio. Un saber que, con relación a lo metafísico, sentimos alejado de toda solemnidad esotérica y al que podemos suponer diseminado en un abanico que se abre desde la experiencia estética a la experiencia ética y la experiencia mística. En cuanto al rol que cumple el paisaje y lo que hemos denominado su potencial epistémico, expondremos a continuación los principales lineamientos de una perspectiva ontológica con sus respectivas implicancias epistemológicas.

\section{LA SERIE ONTOLÓGICA Y EL PAISAJE COMO COPRODUCCIÓN SUJETO-OBJETO}

El principal rasgo del paisaje que lo determina como medio y condición de posibilidad de un saber experiencial es su carácter de interfaz entre lo físico y lo metafísico. Así ha sido percibido desde hace siglos por la filosofía y la cultura china, en las que el paisaje es considerado un puente de acceso natural a la armonización con el Tao, dando lugar, por caso, a una concepción de la pintura del paisaje como viaje espiritual (Shenyou) durante la dinastía Song (960-1279), en la que florece el paisajismo en China ${ }^{10}$. También podemos pensar en el milenario arte de la jardinería, que tanto en Oriente como en Occidente ha dado testimonio de estar vinculado a la

timar los profundos vínculos que muchas veces se generan entre la experiencia histórica (épica o trágica) y la experiencia estética en la modernidad tardía.

${ }^{8}$ Cf. F. Nietzsche, El nacimiento de la tragedia, Alianza, Madrid, 1997, p. 39, y F. Nietzsche, La voluntad de poderío, Edaf, Madrid, 1990, p. 463.

9 Cf. M. Heidegger, «La esencia del habla», en De camino al habla, Odós, Barcelona, 1987, p. 143. 2014, p. 61.

${ }^{10}$ Cf. J.A. Mezcua López, La experiencia del paisaje en China, Abada Editores, Madrid, 
experiencia contemplativa y la purificación mental y espiritual. O si no, recordar a Henry David Thoreau deteniéndose a afirmar, en algún recodo de su Walking, que "por supuesto no tiene sentido dirigir nuestros pasos hacia los bosques si ellos no nos llevan más allá» ${ }^{11}$. Podríamos abundar en ejemplos y algunos como los mencionados constituyen excelentes entradas para pensar la experiencia estética junto con la metafísica, dándonos la pauta de una conexión ontológica profunda, así como de las estrategias desarrolladas por el humano en su relación con lo inhumano a través del paisaje. Pero si queremos atenernos a su aptitud formal para ejercer las funciones de interfaz entre lo físico y lo metafísico (en el sentido técnico del término que define la interfaz como una zona de comunicación o acción de un sistema sobre otro) deberemos necesariamente dar cuenta de su propia complexión fenoménica, así como de su ubicación ontológica respecto de la relación entre el humano y lo inhumano. Más allá del planteo metafísico, estimo que es la idea que subyace en las declaraciones de la UNESCO para la constitución del patrimonio ambiental de la humanidad, de 1992, en las que el paisaje se revaloriza precisamente por su carácter de interfaz entre cultura y naturaleza, en el marco de la protección de la «herencia tangible e intangible» de los pueblos y de los seres humanos en genera ${ }^{12}$.

Como interfaz, en suma, el paisaje corresponde a una zona de interacción con la naturaleza, que desde el punto de vista de la metafísica puede ser considerada también una zona de pasaje y encuentro con eso "otro" que podemos reconocer como una dimensión de trascendencia, ya sea bajo la forma de una trascendencia absoluta, como en el pensamiento judeocristiano, o de una trascendencia en la inmanencia, vista desde una metafísica fenomenista. Alteridad que quizá debiéramos dejar sin determinar con el fin de resguardarla de las certezas absolutas de la religión y la ciencia, que se experimenta de muchas maneras pero que en general se refiere al misterio de la existencia, al ser y al «ahí» (la Madre Tierra, la physis) de donde provenimos y adonde volvemos. De manera tal que, de acuerdo a una primera aproximación ontológica referida a la totalidad del ente, podemos ubicar al paisaje como fenómeno dentro de una serie virtual de la que formaría parte y que estaría compuesta por el Ser, la Naturaleza, el Paisaje y el Humano, mas no sólo como un nivel intermedio, sino como constituido por los «elementos» de la serie, gracias a que participa realmente de los mismos en su equiparación con el mundo, diferenciándose a la vez de éste. Una serie virtual, por cierto, que concebimos a los fines de poder pensar el ser desde una perspectiva dinámica que pueda dar cuenta de su devenir, así como de los diversos niveles con que comprendemos su naturaleza.

Respecto de su propia complexión ontológica lo primero que podemos decir del paisaje es que se trata de una construcción subjetiva-objetiva, y junto con ello que no se trata de una cosa, coincidiendo en esto con los principales actantes de

${ }^{11}$ Cf. H.D. Thoreau, Caminar, Interzona, Buenos Aires, 2016, p. 23. Cursivas en el original.

12 Cf. K. TAYLOR, Landscape and memory: cultural landscapes, intangible values and some thoughts on Asia, en 16 th ICOMOS General Assembly and International Symposium: «Finding the spirit of place-between the tangible and the intangible-», Quebec, 2008, p. 4. 
nuestra metafísica, que son la naturaleza y el ser, siendo la primera una totalidad heterogénea pero sin partes, mientras que el segundo incluye lo sido, lo porvenir y lo posible que mantiene abierto el flujo del devenir. En el caso del paisaje no es, por cierto, por la misma razón que decimos que no es un ente como los demás entes, ya que tal como lo comprendemos habitualmente el paisaje es algo, e incluso algo que se caracteriza por representar un recorte en una totalidad virtual. ¿Pero qué tipo de ente sería ese ente que no es una cosa y sin embargo es algo? Ante una primera aproximación lo primero que se nos muestra es que no es un ente que corresponda a ninguna de las categorías establecidas para los entes reales, imaginarios, simbólicos o materiales, naturales o artificiales; o mejor, y esto es lo importante, es un tipo de ente que participa de todas estas categorías ontológicas. Es algo objetivo, puesto que está ahí: el turismo consiste precisamente en ir de visita a los lugares en los que el paisaje se exhibe como tal; por lo tanto está ahí. Sin embargo, sólo acontece en la medida en que lo percibimos, ya que lo que para algunas personas no es más que parte del hábitat y del mundo para otras constituye un paisaje, y en cuanto tal implica determinadas tonalidades afectivas que lo caracterizan como un paisaje desolado, sereno, acogedor o tenebroso, conectando con el pathos afectivo-espiritual que nos caracteriza como existentes. En ocasiones implicando en sí mismo un doble movimiento: una expansión de la mirada hacia la intuición del todo que se expone "como algo" (un todo relativo a su unidad) y la retrorreferencia al espíritu a partir de la mirada, cuando eso que se contempla «como algo» activa - ha activado ya en cuanto la contemplación sucede- los resortes espirituales de la sensibilidad. Experiencia en la que nos sentimos envueltos por completo en el acontecimiento de eso que llamamos paisaje.

Si nos referimos a la experiencia del mismo, el paisaje se nos revela, pues, antes que como un objeto como un acontecimiento, como algo que sucede. Si nos referirnos en cambio a su carácter objetual, digamos, como para poder sacarle una foto, el que queda en la foto, estaríamos hablando sólo de un aspecto del mismo; y es notable cómo en este caso la experiencia se muestra por defecto, que es lo que nos pasa cuando pretendemos fotografiar momentos que nos conmueven profundamente con el fin de guardar esa especie de revelación espiritual-sensible, que inevitablemente se nos pierde. Sin embargo, el paisaje está ahí, arraigado en una estructura geológica y la mayoría de las veces habitado, transitado por el ser humano. Actual y a la vez virtual, desafiando el principio de identidad que rige las ontologías clásicas. Y quisiera destacar que no se trata de una simple polisemia por la cual el término adquiriría diversas significaciones según el uso, sino de una característica propia del devenir paisaje que se nos revela como un evento, a la vez que objetivo, subjetivo; a la vez que real, ficcional; a la vez que material, simbólico y espiritual. Un ente con la forma del evento que revela una identidad no objetual, dinámica y heterogéneamente constituida. Así se lo piensa incluso desde la geografía, junto con el requerimiento de un método morfológico para su estudio. En palabras de Eduardo Martínez de Pisón:

El paisaje responde a toda la secuencia que va desde las fuerzas generadoras de formas territoriales a la concreción material de éstas, a la expresión final que presentan e incluso a sus cambios y a la representación cultural adquirida y otorgada. El paisa- 
je-forma estricto, situado en el centro de la secuencia, que es su expresión geográfica, resulta de la relación entre tres niveles de configuración: una estructura en que se fundamenta, una forma en que se materializa y una faz en que se manifiesta ${ }^{13}$.

Tres niveles de configuración con los que la geografía trata de fijar el devenir con que se constituye el paisaje, debiendo soslayar -por mor de la construcción de la objetividad científica- la singularidad del paisaje desde un punto de vista estético-existencial, que es el que tiene lugar en nuestras experiencias personales y el que puede ser ocasión de pasaje en el sentido de la experiencia estética-metafísica. Como es de suponer, es en este sentido que avanzamos con nuestra idea del paisaje como interfaz, dando por sentado el valor positivo de una experiencia estéticamente impura -en el sentido de estar mezclada con otras esferas de la experiencia- que si bien podemos discernir de estas otras formas de la experiencia, resultan inseparables entre sí en el proceso vital que se produce con la experiencia vivida, más allá de la instantánea fotográfica que pueda tener lugar en ese estar o andar por el paisaje. Es más, es el carácter de evento y coproducción el que es puesto en acto y desplegado en sus posibilidades más diversas con el andar estético-existencial, que no se reduce, en principio, a una actividad artística, aunque pueda desembocar en ésta si ponemos a la experiencia en marcha en el marco de una poética. Puesto que, de hacerlo, estaríamos orientando implícitamente la experiencia hacia la unidad virtual de la obra a partir de la unidad que caracteriza por definición a toda experiencia. No obstante lo cual, desde el punto de vista de la metafísica-estética no es la producción artística lo que más interesa, sino la experiencia, y especialmente las implicancias de la experiencia estética en el proceso transfísico (entre el humano y lo inhumano a través del paisaje) en que se resuelven los aspectos atencionales, emocionales y cognitivos de la misma. En el fondo, lo que subyace es la ya siempre previa imbricación del ser humano en la naturaleza, que se ve activada por la forma en que se determina la experiencia del paisaje.

\section{4. (PROTO)ARTE DE LA NATURALEZA Y ARTE DE LOS PUEBLOS}

Una segunda perspectiva ontológica nos lleva a considerar al paisaje como protoarte. No digo como arte sin más porque históricamente hemos considerado al arte como un producto humano por definición, habida cuenta de que tanto la estética como las bellas artes lo han definido desde un paradigma subjetivista aún vigente en la actualidad. En todo caso, por cierta cautela intelectual, propondría la denominación "protoarte de la naturaleza" para referirme a un estado germinal de eso que llamamos arte tal como se encontraría en la naturaleza misma, por así decir,

13 E. Martínez de Pisón, «Epílogo», en J. Nogué (ed.) La construcción social del paisaje, Biblioteca Nueva, Madrid, 2016, p. 327. 
antes del paisaje, intencionando una anterioridad ontológica con el «antes» antes bien que cronológica. En esa línea lo percibiría, grosso modo, el Romanticismo (al que nos hemos referido en más de una oportunidad), pero bien podemos retrotraernos a la filosofía de Plotino, en el siglo in de la era cristiana, o bien remitirnos a tradiciones por completo diferentes como la china, donde se ha trabajado con la mayor profundidad la cuestión metafísica en relación con el paisaje. En lo que sigue ofrezco una serie de hitos referidos a la comprensión del carácter autopoiético del ser (y de la naturaleza) con que asociamos la idea de protoarte del paisaje, cuya pertenencia a contextos culturales e históricos completamente diferentes da cuenta del carácter objetivo que le podemos atribuir con verosimilitud a dicha idea.

En Enéada III, Plotino, en medio de una serie de reflexiones por completo ajenas a la cuestión del arte, le adscribe a la naturaleza no sólo un carácter creativo sino también contemplativo, en el marco de una cascada ontológica de lo existente en la que el acto creador originario, adscripto a la divinidad, resuena en cada partícula de la creatura. Desde la más ínfima a la más excelsa, en un proceso en el que la potencia creadora no parece ceñirse a la clásica comprensión del acto performativo del Logos (el arjé del fiat verbal que crea desde un poder total), sino pensando en un Logos que actúa por vía de la naturaleza sensible de las imágenes y por la contemplación. Un acto por el que la naturaleza, los entes y los acontecimientos se desplegarían permanentemente. H. Padrón lo resume de la siguiente manera:

La última expresión helénica del concepto de physis está determinada por la filosofía de Plotino; para éste la physis es el Logos que produce las formas y las suministra a la materia. La physis deriva de la contemplación del Alma, y ella misma es contemplación, y como toda realidad inteligible contemplando al Uno produce ${ }^{14}$.

Con Plotino queda así resignificada la concepción griega del concepto de physis tras pasar por el tamiz de la revelación judeocristiana, subordinándose al Uno a la vez que manteniendo su carácter autopoiético de acuerdo a la dinámica misma de la contemplación. Pues (dice la Naturaleza en una prosopopeya que le facilita Plotino):

... lo originado es el objeto de mi contemplación, mientras yo guardo silencio, y un objeto de contemplación originado por naturaleza, y que, como yo he nacido de una contemplación así, me corresponde tener una naturaleza aficionada a contemplar ${ }^{15}$.

Schelling, por su parte, habiendo apaciguado el espíritu revolucionario del Proyecto... referido más arriba, en La relación del arte con la naturaleza encauza su idea de metafísica-estética por detrás de los criterios de lo que debiera ser el verdadero arte, afirmando que «nos parece excelente una obra de arte en la medida en

${ }^{14}$ H. PAdrón, «Naturaleza, Naturalismo y Ecología», en Massini Correa y otros, Ecología y Filosofía, Edium, Mendoza, 1993, p. 136.

15 Plotino, Enéadas III-IV, (trad. J. Igal) Gredos, Madrid, 1982-1985; Enéada III 8, 5-7, p. 242. 
que se nos muestre en ella esta fuerza no falseada del poder creador y la actividad de la naturaleza ${ }^{16}$, debiendo "alejarse del producto o la criatura, pero para elevarse hasta la fuerza que los crea y apoderarse espiritualmente de ella», pues "el artista debe rivalizar con aquél espíritu de la naturaleza que actúa mediante la forma y la configuración, solamente como hablando por imágenes sensibles»" ${ }^{17}$. Una nueva referencia al carácter expresivo de la naturaleza misma, cuyo fundamento, en última instancia, se encontraría más allá de las formas, pues:

Lo único que da belleza a la obra de arte, a su conjunto, no puede ser la forma, sino algo que está más allá de la misma: la esencia, lo universal, la mirada y la expresión del inmanente espíritu natural ${ }^{18}$.

Ambos, tanto Schelling como Plotino, postulan un poder activo y creador en la naturaleza que se deriva de una instancia de carácter espiritual, activa y productiva; idea con la que coincidiría en términos generales, excepto por la caracterización que hagamos de esa instancia en la que se encuentra implicada nuestra concepción de lo divino y del ser. En ambos pensadores con una fuerte influencia de la metafísica platónica y judeocristiana que sin duda marca una gran diferencia con nuestra transfísica de la inmanencia ${ }^{19}$; pero una diferencia menor o más bien inexistente en lo que concierne al carácter autopoiético de la naturaleza de la que se desprende el paisaje. Preguntarse en qué momento surge éste de la naturaleza es como preguntarse cuándo empieza la obra de arte, en qué trazo, compás o frase; en qué pliegue obediente a las grandes leyes del mundo físico el plano de la materia deviene plano de la composición. Y cómo no imaginar el acto poiético de la existencia toda como un acto divino, ya que sabemos que de cualquier manera es un acto inhumano. En todo caso diabólico, aunque de acuerdo a los datos con que contamos parece estar implicado casi siempre el cielo en el paisaje de lo sagrado, ya sea que averigüemos por el lado de la etimología de divino (que nos conduce del latín divinus a la raíz indoeuropea dyeuldyu, que significa luz del día, común a zeus como a deus, seres de luz, celestiales, lo mismo que Júpiter) o bien que nos quedemos con una síntesis del gran investigador de las relaciones entre lo humano y lo divino que ha sido Mircea Elíade, quien nos prepara a recibir sus tesis acerca de los orígenes de la religión, sosteniendo que «la simple contemplación de la bóveda celeste basta para desencadenar una experiencia religiosa ${ }^{20}$.

Es tal vez en la tradición china donde se concibe de manera más natural el protoarte de la naturaleza, junto con el carácter divino de ésta en el sentido pagano

${ }^{16}$ F. Schelling, La relación del arte con la naturaleza, Sarpe, Madrid, 1985, p. 68.

${ }^{17}$ Idem, p. 69.

${ }_{18}$ Ibid.

19 "Transfísica de la inmanencia» alude a una teoría del ser concebido bajo el paradigma de la inmanencia en el marco de una metafísica fenomenista, mientras que el término transfísica nos remite a la metafísica como actividad dentro de la multiplicidad de la inmanencia, a través de la Physis y la multiplicidad de su apariencia.

20 M. Elíade, Lo sagrado y lo profano, Labor, Colombia, 1994, p. 102. 
de las religiones naturales. Experiencia que a lo largo del tiempo da en generar eso que llamamos arte en torno al eje del paisaje, siendo éste una de las vías más importantes de acceso al saber del ser que es del Tao, valga remarcar, intrínseco a la naturaleza como al ser humano. También en el I Ching -lo que es decir en la filosofía taoísta- el acto de la creación es un acto supremo, y lo creativo podríamos decir que se destaca como potencia, aun en un sistema de figuras, cualidades y potencias que no se caracteriza por estar jerárquicamente determinado. E igualmente vinculado al cielo, como se manifiesta en esa obra de arte de la humanidad que es el Templo del Cielo en la actual Beijing. El primer hexagrama del I Ching es Ch'ien, lo Creativo, el Cielo; su composición en trazos no partidos corresponde a la protoenergía primaria luminosa, espiritual, activa; y como reza su descripción desde la perspectiva macrocósmica, «con respecto al acontecer universal se expresa en el signo la fuerte acción creativa de la divinidad $»^{21}$.

En sintonía con Schelling respecto de la relación del arte (del artista en verdad) con el ser profundo del siendo $0^{22}$, aunque por cierto desde una tradición y un paradigma por completo diferentes, Tsung Ping refiere en El gozo de pintar el carácter objetivo del devenir arte del paisaje, a partir de toda una poética del encuentro requerida por parte del artista, quien debe esforzarse por sintonizar con la naturalidad fluente del universo:

Cuando se establece este contacto espiritual -dice Tsung Ping- las formas verdaderas quedan realizadas y comprendidas y se vuelve a capturar su espíritu [...]. Por ańadidura, el espíritu no posee una forma propia, sino que adquiere forma merced a las cosas. La ley interna de los objetos ( $l i)$ puede trazarse a través de la luz y la oscuridad. Si los objetos están hábilmente representados son la misma verdad ${ }^{23}$.

Habría que dedicarle todo un capítulo al significado de esa ley de producción interna ( $l_{i}$ así como al espíritu (qi) para comprender la profunda relación que mantiene la naturaleza con el paisaje y el Tao en el pensamiento chino, en el que, como refiere Rowley, la voz qi o espíritu resume la presencia del Tao en la pintura, comprendida explícitamente desde Han Zhuo como una práctica que opera con las fuerzas creadoras y comparte la misma energía del $\mathrm{Tao}^{24}$.

${ }^{21}$ R. Wilhelm, I Ching, Sudamericana, Buenos Aires, 2009, p. 79.

22 Uso el gerundio sustantivado siendo, en vez de «ser», para remarcar el carácter dinámico de lo existente. El término equivale al to on griego y al ens latino: «lo que es», que si bien han sido traducidos muchas veces como «ente» y como «el ser», considero que en ambos casos connotan un carácter objetual y estático inadecuado a su naturaleza. No obstante lo cual continúo usando (el) «ser» como sinónimo de (el) «siendo», debido al uso habitual en nuestra lengua. Por su parte uso aquí el término ser para referirme al ser del siendo: su naturaleza, esencia o rasgos determinantes, independientemente de cómo se lo conciba.

${ }^{23}$ Tsung PING, «El gozo de pintar», en Lin Yutang, Teoría china del arte, Sudamericana, Buenos Aires, 1968, p. 46.

${ }^{24}$ Cf. G. Rowley, Principios de la pintura china, Alianza, Madrid, 1981, p. 60. 
En la teoría clásica del arte chino las prevenciones para el artista no difieren mucho de las que señala Schelling respecto del trato con la obra y con la naturaleza a ser interpretada. Y menos aún la concepción del carácter creativo de lo divino en la naturaleza, lo que da cuenta de una percepción y una interpretación que trasciende la autoría de tales o cuales filósofos, para conformar un modo de relacionarnos a través de un pensamiento en gran medida colectivo, transindividual, que traspone al plano de las ideas y del arte una experiencia de alguna manera común. Si tuviéramos que mencionar a alguien más que no podría faltar a esta elaboración de la experiencia de la naturaleza y lo místico por parte de la filosofía, sería, por cierto, Friedrich Nietzsche, dándoles forma y contenido a las potencias creadoras con la pareja de lo apolíneo y lo dionisíaco: «Potencias artísticas que brotan de la naturaleza misma, sin mediación del artista humano... $\nu^{25}$, sobre el fondo de una multiplicidad última en la que se juega el juego diferencial de la (igualmente múltiple) voluntad de poder-ser, que en última instancia es concebida en su filosofía como fuerza configuradora bajo el modelo del arte.

«El arte empieza tal vez con el animal», dudan a la vez que afirman Deleuze-Guattari en el capítulo 7 de ¿Qué es la filosofía? ${ }^{26}$, vinculando ese arte no humano a la delimitación del «territorio-casa», donde el territorio implica la emergencia de cualidades sensibles puras: «Sensibilia que dejan de ser funcionales y se vuelven rasgos de expresión", dicen más adelante, trabajando pacientemente la imagen-concepto del venir a ser del arte desde antes del humano, con el que subrepticiamente y como resguardándose en el pretexto del arte se aventuran en las incertezas del ser. Del venir a ser de lo que hay, al que imaginan en términos de relaciones de contrapunto como una especie de dinámica básica, elemental, del juego de la multiplicidad. Relaciones de contrapunto por las que se forman compuestos de afectos y sensaciones no humanas, anteriores al humano, y de las que, en todo caso, el humano forma parte pero que no determina desde una posición privilegiada.

¿Pero estamos hablando de lo mismo con Deleuze-Guattari que con Schelling, Nietzsche, Tsun Ping y Plotino? No y sí. No, porque son diferentes aproximaciones desde supuestos diferentes y desde diferentes intereses. Sí, porque no cesamos de lanzar las redes del pensamiento en las zonas fronterizas de la razón con el misterio, desde una experiencia compartida e históricamente elaborada acerca del protoarte del paisaje en la naturaleza. En términos técnicos, es posible que el proceso atencional de la relación estética (el comportamiento estético que podemos adoptar o no) coincida con el carácter poiético por el que se revela el protoarte de la naturaleza. Tal sería el caso del ready made, o mejor, para referirnos a la naturaleza natural, de l'objet trouvé, que si mal no recuerdo se menciona en algún diálogo platónico, hablando acerca de una piedra o una madera pulida por el mar sobre la arena de la playa. Género al que podríamos adscribir una de las exquisitas formas del arte el original.

${ }_{25}$ F. Nietzsche, El nacimiento de la tragedia, Alianza, Madrid, 1997, p. 46. Cursivas en ${ }^{26}$ Cf. G. Deleuze y F. Guattari, ¿Qué es la filosofía?, Anagrama, Barcelona, 1993. 
oriental de encontrar paisajes en las piedras (suiseki do) sin intervención alguna en su composición. En ese caso al acto de la esthesis le es consustancial el de la poiesis, sin que sea necesario recaer en un subjetivismo burdo respecto de la experiencia estética, ya que si la elegancia de una flor o la fuerza del árbol, como piensa Genette, son propiedades relacionales (esto es, no de los objetos sino de nuestro trato con ellos) que "sobrevienen" a las propiedades de los objetos y traducen nuestra apreciación positiva o negativa (el viejo tema de la belleza ${ }^{27}$, son propiedades que, en vez de traducir nuestra afección como quien saca algo afuera de alguien, con referencia a algo, acontecen en nosotros en la interacción con el mundo que es también afectiva. De manera tal que, desde el punto de vista del acontecimiento de lo existente, cabe suponer que somos atravesados por las fuerzas afectivas y las modulaciones perceptuales del mundo en nosotros, en lo que sería una traducción primaria (de corte puramente estésico) de la naturaleza en nosotros, anterior a la traducción de nuestros afectos al considerar la elegancia de la flor. En esa dirección nos explicaríamos el acontecimiento del protoarte en la naturaleza como un acontecimiento, a la vez que subjetivo, objetivo, más allá de las formas más explícitas del arte del paisaje que podemos hallar en la combinación de la naturaleza con el habitar humano.

Del protoarte del paisaje en la naturaleza al arte del paisaje de los pueblos hay una transición prácticamente imperceptible. No es difícil de constatar, en los más diversos lugares del mundo, cómo eso que llega a convertirse en un principio de la arquitectura que es la integración armónica de las construcciones al medio natural es algo que de manera espontánea han llevado a cabo las más diversas culturas. Empleando los mismos materiales que provee la Tierra y adecuándose a las modulaciones del territorio y el clima, las edificaciones humanas han sabido respetar esa especie de principio implícito con el que regir las construcciones. De ahí en más, el paso del espacio natural al territorio y al hábitat construido no habría de corresponder más que al tránsito de un proceso por el que lo natural y lo artificial componen mundo. Claro que para hablar del arte del paisaje de los pueblos tenemos que revisar nuevamente nuestras categorías modernas sobre qué es el arte, basados no en la producción individual de cierto tipo de artefactos, sino en la elaboración colectiva y anónima del mundo de la vida por parte de una comunidad. De manera tal que a las cualidades físicas del paisaje, forjadas en el lento devenir del tiempo de la naturaleza, se les añaden aquellos rasgos estético-culturales que caracterizan al paisaje como escenario de la actuación humana, haciendo del mismo un entorno portador de identidad. Y en esa ontología viva (ya no como ciencia sino como devenir de lo real) se traza una semiosis igualmente anterior a toda semiótica, sobre la que se acaban delineando los rasgos idiosincráticos de un ethos o de un eventual habitar y estar humano.

Por su parte, como obra de arte el paisaje acaba desplegando todas sus potencialidades epistémicas, en primer lugar haciendo de estímulo sensorial y afectivo para una exploración que puede ser tanto exterior como interior, dentro de un abanico

27 Cf. J-M. Schaeffer, La experiencia estética, La Marca, Buenos Aires, 2018, p. 35. 
muy amplio que va desde nuestras relaciones con el medioambiente a las posibilidades de abrir las puertas de la experiencia mística. No interesa tanto si pertenece o no a la institución del arte como el hecho de comportase como tal, abriendo un juego que a la vez que se mantiene abierto por naturaleza termina de completarse con el humano. Abriendo todo el tiempo un abanico de significaciones mediante el que la obra proyecta mundos posibles con cada espectador, quien de esa manera deja de serlo, implicado ya ontológicamente en la obra misma que lo toma como elemento. Sólo que, lo que en el común de las obras se da como una multiplicidad virtual de significaciones que se disparan con el encuentro entre uno y la obra, en el caso del paisaje se traduce en una multiplicidad de direcciones u opciones para nuestro andar en el paisaje o para habitarlo. Pues andarlo también es una forma de habitarlo. Y quizá de las más productivas en su carácter de interfaz, combinando esa peculiar forma de arte que es el paisaje con el arte del andar. Una práctica que ha sido llevada a cabo y pensada en más de una oportunidad como arte del caminar, pero que podemos hacer extensiva a cualquier otra forma del andar; máxime teniendo en cuenta que desde una perspectiva existencial todo estar es de alguna manera un ir y un $a_{n d a r}^{28}$. Con éste indudablemente la experiencia del paisaje se potencia, dando lugar a una experiencia cuyo escenario es la vida misma, a la que volvemos con rudimentarias herramientas para convertirla en camino de conocimiento, de saber de sí y de lo otro, de comprensión hermenéutica, elaboración simbólica y participación energética.

ReCibido: febrero de 2020; ACEPTADo: julio de 2020

${ }^{28}$ La parte práctica de la metafísica-estética del paisaje contempla el desarrollo de unas poéticas de la experiencia de las que forman parte las poéticas del andar como prácticas más o menos pautadas y desarrolladas en el terreno, a través de las cuales tienen lugar tanto las experiencias puntuales (las vivencias) como la generación de una experiencia compleja capaz de desarrollarse como saber. 